\title{
ADAPTAÇÃO DO MÚSCULO ESQUELÉTICO AO EXERCÍCIO FÍSICO: CONSIDERAÇÕES MOLECULARES E ENERGÉTICAS
}

\author{
ADAPTATION OF SKELETAL MUSCLE TO PHYSICAL EXERCISE: MOLECULAR AND ENERGY \\ CONSIDERATIONS
}

\section{Artigo de Revisão \\ REVIEW ARTICLE \\ ARtículo de REVISIÓN}

\begin{abstract}
ADAPTACIÓN DEL MÚSCULO ESQUELÉTICO AL EJERCICIO FÍSICO: CONSIDERACIONES MOLECULARES Y ENERGÉTICAS
\end{abstract}

Phablo Abreu'

(Profissional de Educação Física)

José Henrique Leal-Cardoso² (Médico)

Vânia Marilande Ceccatto 3 (Bióloga)

1. Universidade de São Paulo (USP), Departamento de Fisiologia e Biofísica, Instituto de Ciências Biomédicas (ICB), São Paulo, SP, Brasil.

2. Universidade Estadual do Ceará (UECE), Laboratório de Eletrofisiologia, Instituto Superior de Ciências Biomédicas (ISCB), Fortaleza, CE, Brasil.

3. Universidade Estadual do Ceará (UECE), Laboratório de Bioquímica e Expressão Gênica, Instituto Superior de Ciências Biomédicas (ISCB), Fortaleza, CE, Brasil.

\section{Correspondência:}

Departamento de Fisiologia e Biofísica, Instituto de Ciências Biomédicas, Universidade de São Paulo. Av. Prof. Lineu Prestes, 2415, São Paulo, SP, Brasil. 05508-900. phablofisio@gmail.com phablo@icb.usp.br

\section{RESUMO}

Os benefícios para a saúde e as adaptações fisiológicas ao exercício regular são amplamente conhecidos e, com o advento das ciências ômicas e moleculares, revelou-se uma complexa rede de vias de sinalização e moléculas reguladoras que coordenam a resposta adaptativa do músculo esquelético ao exercício. As mudanças orgânicas transientes, porém, são cumulativas no pós-exercício. Elas incluem, de forma principal, a transcrição de genes relacionados aos fatores regulatórios da miogênese, ao metabolismo de carboidratos, à mobilização de gorduras, ao transporte e oxidação de substratos, ao metabolismo mitocondrial através da fosforilação oxidativa e, por fim, à regulação transcricional de genes envolvidos na biogênese mitocondrial. Tendo em vista o grande impacto científico, resumiram-se neste trabalho, além de algumas das principais respostas moleculares sofridas pelo músculo esquelético com o exercício físico, fatores que coordenam a plasticidade muscular para o ganho de desempenho. Foram citadas dezenas de biomarcadores ligados a alguns aspectos moleculares das adaptações do músculo esquelético ao exercício físico, algumas principais vias sinalizadoras e o papel mitocondrial, revelando alguns novos paradigmas para o entendimento desta área científica.

Descritores: exercício; músculo esquelético; biomarcadores; metabolismo energético.

\section{ABSTRACT}

The health benefits and physiological adaptations to regular physical exercise are widely known, and with the advent of the omic and molecular sciences, a complex network of signaling pathways and regulatory molecules that coordinate the adaptive response of skeletal muscle to exercise has been revealed. Transient organic changes, however, are cumulative in the post-exercise period. They mainly include transcription of genes related to regulatory factors of myogenesis, carbohydrate metabolism, fat mobilization, transport and oxidation of substrates, mitochondrial metabolism through oxidative phosphorylation, and finally, the transcriptional regulation of genes involved in mitochondrial biogenesis. Given their great scientific impact, in addition to some of the main molecular responses experienced by the skeletal muscle to exercise, factors that coordinate muscle plasticity for performance gain were summarized in this work. This review mentioned dozens of biomarkers linked to some molecular aspects of skeletal muscle adaptations to physical exercise, some major signaling pathways and the role of mitochondria, revealing some new paradigms for the understanding of this field of science.

Keywords: exercise; muscle, skeletal; biomarkers; energy metabolism.

\section{RESUMEN}

Los beneficios para la salud y las adaptaciones fisiológicas al ejercicio regular son ampliamente conocidos y, con el advenimiento de las ciencias ómicas y moleculares, se ha revelado una compleja red de vías de señalización y moléculas reguladoras que coordinan la respuesta adaptativa del músculo esquelético al ejercicio físico. Los cambios orgánicos transitorios, sin embargo, son acumulativos después del ejercicio. Ellos incluyen principalmente la trascripción de genes relacionados a los factores de regulación de la miogénesis, metabolismo de carbohidratos, movilización de grasas, transportey oxidación de substratos, metabolismo mitocondrial por la fosforilación oxidativa y, en última instancia, la regulación transcripcional de genes involucrados en la biogénesis mitocondrial. Teniendo en cuenta el gran impacto científico, se resumió en este trabajo, además de algunas de las principales respuestas moleculares experimentadas por el músculo esquelético con el ejercicio físico, factores que coordinan la plasticidad muscular en la ganancia del rendimiento. Se citaron decenas de biomarcadores relacionados con algunos aspectos moleculares de las adaptaciones del músculo esquelético al ejercicio físico, algunas de las principales vías de señalización y el papel mitocondrial, revelando algunos nuevos paradigmas para el entendimiento de esta área científica.

Descriptores: ejercicio, músculo esquelético; biomarcadores; metabolismo energético. 


\section{INTRODUÇÃO}

O exercício físico regularmente executado é um fator de estímulo que induz a uma série de adaptações no músculo esquelético. Recentes avanços moleculares, dentro da perspectiva ômica,' como a proteômica e a metabolômica, vem descrevendo e quantificando, de dezenas a milhares de genes, peptídeos, proteínas e metabólitos em uma única amostra biológica, o que tem fornecido importantes informações acerca das modificações moleculares sofridas pelo músculo esquelético, em resposta ao exercício físico. Assim, a já conhecida variedade de benefícios, promovidos pelo exercício físico, vêm sendo progressivamente ligada à vasta rede de vias de sinalização e moléculas reguladoras que coordenam as respostas adaptativas do músculo esquelético ao exercício físico, promovendo o esclarecimento de patologias que promovem progressiva perda de massa muscular como, por exemplo, a sarcopenia no envelhecimento e a caquexia no câncer².

Repetidos episódios de contração muscular promovidos pelo treinamento físico, são potentes estímulos para as adaptações moleculares. Em termos gerais, o músculo esquelético apresenta a destacada maleabilidade de adaptação funcional à atividade contráti|'. Estas adaptações são refletidas por mudanças na expressão de proteínas contráteis e por modificações na função contráti|4. Destaca-se também a adaptação mitocondrial, ${ }^{5}$ a regulação molecular metabólica, ${ }^{6}$ as mudanças no conteúdo de sinalizadores intracelulares, e por fim, as modificações na resposta transcricional ${ }^{8}$.

Neste contexto metodológico de grande impacto científico, buscou-se resumir neste trabalho as principais respostas moleculares sofridas pelo músculo esquelético ao exercício físico. Foram enfocados alguns aspectos moleculares das adaptações do músculo esquelético ao exercício físico, caracterizando-se os principais biomarcadores, algumas principais vias sinalizadoras e o papel mitocondrial, revelando alguns novos paradigmas para o entendimento desta área. Este trabalho baseou-se em quatro bases de dados bibliográficas: PubMed, Web of Science, Scientific Electronic Library Online (SciELO) e Literatura Latino-Americana e do Caribe em Ciências da Saúde (LILACS), nas línguas portuguesa e inglesa. Quanto aos termos, devido às diferenças nos processos de indexação nas bases de dados bibliográficas, optou-se pela busca por termos livres, sem o uso de vocabulário controlado (descritores). Dessa maneira, houve recuperação de um número maior de referências, garantindo a detecção do maior número de trabalhos publicados, conforme proposto por Sin et al. ${ }^{9}$.

\section{Bases moleculares transcricionais e traducionais das adaptações do músculo esquelético ao exercício físico}

O trabalho muscular é caracterizado por uma expressiva indução gênica, proteica e metabólica. As adaptações musculares ao exercício são a base da modificação do estado sedentário para o fenótipo dito exercitado. Estes mecanismos moleculares que governam estas conformações envolvem uma progressiva e gradual alteração no conteúdo de proteínas e atividade de enzimas. Estas adaptações moleculares sofridas pelo músculo esquelético refletem a progressiva adaptação e/ ou repressão de vias específicas de sinalização que regulam a atividade transcricional e traducional. Assim, respostas agudas e adaptações crônicas do músculo esquelético induzidas pelo exercício físico promovem alterações no conteúdo de mRNA, na atividade de enzimas e no conteúdo de proteínas que resultam em ganho de função contrátil, desencadeando ativação ou repressão de vias moleculares de sinalização que regulam a transcrição e a tradução de proteínas (Figura 1) ${ }^{8}$.

A Figura 1 mostra gráfico ilustrativo do comportamento molecular aos repetidos estímulos agudos das sessões de exercício. Estas promoveram um crescimento abrupto do conteúdo de mRNA, porém transitório, retornando à base após a interrupção do estímulo. Entretanto, o contínuo estímulo assinalado pelo treinamento físico, desencadeia um gradual e progressivo aumento do conteúdo de mRNA e proteínas resultando em ganho de performance, desde que o estímulo não seja interrompido, condição esta caracterizada pelo destreinamento.

Assim, as mudanças orgânicas transientes, porém cumulativas, pós-exercício, incluem processos biológicos. Dentre eles, de forma principal, listam-se a transcrição de genes relacionados aos fatores regulatórios da miogênese, ao metabolismo de carboidratos, à mobilização de gorduras, ao transporte e oxidação de substratos, ao metabolismo mitocondrial através da fosforilação oxidativa e, por fim, a regulação transcricional de genes envolvidos na biogênese mitocondria|-10. Evidências demonstram que a expressão de mRNA são elevadas 3 a 12 h após a realização do exercício físico, retornando aos níveis basais em torno de, aproximadamente, $4 \mathrm{~h}^{3}$. As adaptações crônicas induzidas pelo exercício provêm do acúmulo dos efeitos agudos em cada sessão decorrente do estresse mecânico gerado. Os fatores determinantes para as respostas moleculares são a intensidade, a duração, frequência e a modalidade de exercício praticado ${ }^{11,12}$. Veremos a seguir, de forma objetiva alguns biomarcadores destas mudanças.

A regulação molecular promovida pelo exercício físico prediz que uma única sessão de exercício altera a atividade de fatores transcricionais. Dentre estes citam-se o Myocyte Enhancer Factor-2 (MEF2), que representa uma família de fatores de transcrição controladores da expressão de importantes genes regulatórios da diferenciação celular e desenvolvimento, ${ }^{13}$ as Histone Deacetylase Activities (HDACs), histonas desacetiladas, que possuem papel fundamental no remodelamento da cromatina ${ }^{14}$ e fatores como os Nuclear Respiratory Factors (NRFs), que ativam a expressam de genes metabólicos regulando o crescimento celular e a replicação e transcrição do DNA mitocondria|'15.

A estabilidade de proteínas e a localização sub-celular de complexos fatores transcricionais dentro do núcleo e na mitocôndria são também afetados $^{16,17}$. Assim, a elevada expressão gênica durante estímulo da contração muscular promovido pelo exercício físico, desencadeia, progressivamente e gradualmente, a síntese de proteínas responsáveis pelos ajustes intrínsecos estruturais e funcionais do tecido muscular esquelético ao treinamento físico ${ }^{18}$. Estes ajustes contribuem coletivamente para maximizar a entrega de substrato para a síntese de energia, a capacidade respiratória mitocondrial e a função contrátil durante o exercício, resultando em otimização da performance em futuras atividades físicas, menor perturbação da homeostase orgânica e consequentemente, aumento da resistência a fadiga ${ }^{11,19}$.

A ativação de vias moleculares intracelulares desencadeadas pela contração muscular durante exercício físico regula a plasticidade do músculo esquelético, de maneira que a tensão mecânica gerada provoque alterações que ativam ou inativam determinadas vias de sinalização celular, tais como o turnover da adenosina trifosfato (ATP), o fluxo de cálcio, o balanço redox, a produção de espécies reativas de oxigênio (EROs) e a pressão intracelular do oxigênio, que por sua vez causam mudanças, resultando em perturbação do meio celular, implicando em adaptação muscular ao exercício 3,11,12.

O comportamento molecular aos repetidos estímulos agudos das sessões de exercício e aos estímulos ou adaptações crônicas do treinamento físico sobre o conteúdo de mRNA e de proteínas no músculo esquelético estão dispostos esquematicamente na Figura 1. Estímulos agudos promovem crescimento abrupto do conteúdo de mRNA, porém transitório, retornando à base após a interrupção do estímulo. Esta elevação transiente do conteúdo de mRNA é insuficiente para alterar a característica fenotípica do tecido muscular esquelético, retornando à condição basal após cessação do trabalho mecânico (sessão de exercício), cerca de $24 \mathrm{~h}$. Entretanto, as repetidas sessões de exercício caracterizado 


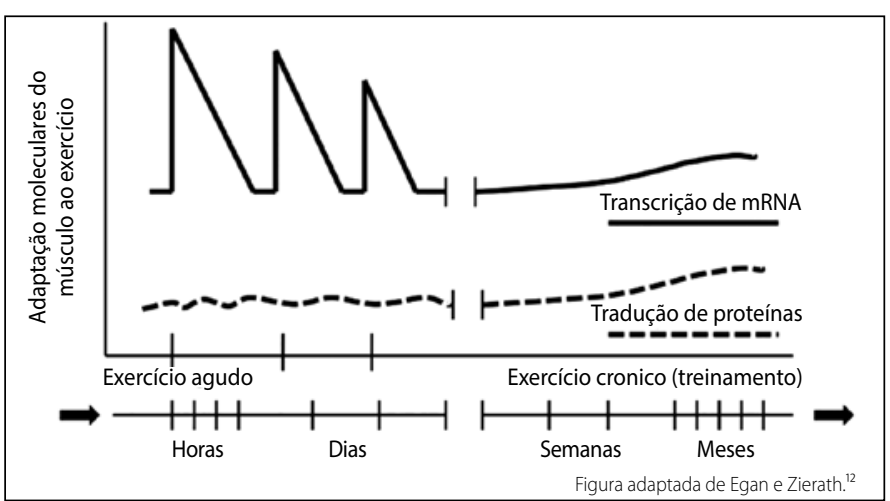

Figura 1. Adaptações moleculares agudas e crônicas do músculo esquelético ao exercício físico.

pelo contínuo estímulo (treinamento físico), desencadeia um gradual e progressivo aumento do conteúdo de mRNA e de proteínas resultando em ganho de performance. Dessa forma, os efeitos somados de cada sessão de exercício, resultam a longo prazo, em aumento da função contrátil, aprimorada seleção de substrato energético específico para o trabalho mecânico, transcrição de genes relacionados aos fatores regulatórios da miogênese, eficiente transporte/captação de carboidratos, aumento da mobilização e oxidação de gorduras, elevada atividade mitocondrial através da fosforilação oxidativa e, por fim, aprimorada regulação transcricional de genes envolvidos na biogênese mitocondrial.

\section{Regulação molecular do músculo esquelético ao exercício aeróbico: adaptações metabólicas e mitocondriais}

A contração muscular induz diversas modificações em complexas vias de sinalização que regulam a plasticidade do músculo esquelético, dentre elas, a elevação do turnover do ATP, do fluxo de cálcio, do balanço redox, da produção de espécies reativas de oxigênio e o aumento da pressão intracelular de oxigênio, ativando sensores celulares que codificam a perturbação do meio ocasionados pela tensão mecânica da contração muscular e ativam processos transcricionais. A contínua perturbação do meio ocasionada pelo treinamento físico promove no tecido muscular mudanças adaptativas morfológicas e fisiológicas, resumidas na Figura 2.

A Figura 2 representativa ilustra resumidamente, as adaptações moleculares do músculo esquelético ao exercício. Os estímulos bioquímicos e biomecânicos gerados pela contração muscular modificam a homeostasia do músculo esquelético que são detectados por sensores intracelulares que desencadeiam um sinal levando a ativação de uma complexa via de sinalização intracelular que incluem moléculas (proteínas) quinases, fosfatases e deacetilases, que promovem o acionamento de alvos específicos, resultando em transcrição e tradução de proteínas. A magnitude desses efeitos são dependentes, principalmente, da intensidade e duração do exercício, que induzem alterações na tensão mecânica, turnover do ATP, fluxo de cálcio, balanço redox e produção de espécies reativas de oxigênio (ROS), e hipóxia (balanço do $\mathrm{O}_{2}$ ) intracelular.

Um importante regulador celular é o fator transcricional Hypoxia-Inducible Factor (HIF), que ativa uma complexa via transcricional em resposta à pressão parcial intracelular de oxigênio $\left(\mathrm{PiO}_{2}\right)$, incluindo a regulação de genes envolvidos no metabolismo energético, eritropoiese, angiogênese e apoptose ${ }^{20}$, e de maneira análoga ao exercício ${ }^{21}$. O HIF é um fator de transcrição heterodimérico composto por duas subunidades HIF-1a e HIF-1ß. Em condições de normoxia, a hidroxilação do HIF-1a ocorre pela enzima prolil hidroxilase (PHD), que rapidamente aciona a ligação da proteína ubiquitina E3 ligase supressora de tumor von Hippel Lindau (pVHL) para o HIF-1 a, sinalizando a degradação proteossômica. Contudo, durante hipóxia ou condições de reduzida $\mathrm{PiO}_{2}$, a atividade da enzima PHD é inibida, o que permite a estabilização e translocação de HIF-1a para o núcleo formando um complexo ativo com o fator HIF-1 $\beta .^{20,21}$ Assim, a regulação transcricional do HIF durante baixas $\mathrm{PiO}_{2}$ provê a sobrevivência celular, aumentando a habilidade celular de obter ATP a partir de vias independentes da participação do $\mathrm{O}_{2}^{22}$. Nessas condições, embora a $\mathrm{PiO}_{2}$ em condições de repouso no músculo esquelético seja de $1 / 5$ da pressão de $\mathrm{O}_{2}$ do ar inalado, o exercício agudo reduz a $\mathrm{PiO}_{2}$ muscular na ordem de $1 / 40^{23}$. Assim, o aumento do HIF-1 a no exercício agudo já estabelecido, coincide com a diminuição da expressão de pVHL ${ }^{24}$, revelando um importante papel do HIF em promover benefícios metabólicos para o desempenho físico em atletas ${ }^{25}$.

A proteína quinase ativada por AMP (AMPK) é uma serina/treonina quinase que modula o metabolismo celular através da fosforilação de enzimas metabólicas ou via regulação transcricional ${ }^{26}$. A ativação desta proteína é regulada alostericamente por déficit celular de energia pelo aumento da razão AMP/ATP e razão creatina/fosfocreatina durante eventos como, por exemplo, o exercício intenso, estresse celular por toxinas que depletam o conteúdo de ATP, e estresse oxidativo derivado da privação de glicose ${ }^{27}$. Assim, a AMPK age como um sinalizador intracelular do status de energia, respondendo ao grau (intensidade) da contração muscular através do aumento da fosforilação e atividade enzimática ${ }^{28,29}$. Em termos gerais, a AMPK é ativada para conservar o conteúdo de ATP, inibindo as vias de biossíntese de glicogênio e proteínas, reciprocamente ativando a sinalização catabólica (oxidação de gorduras e transporte/captação de glicose) para restaurar o status de energia celular ${ }^{27}$. Cronicamente em resposta ao treinamento físico, relatórios evidenciam que a AMPK promove a expressão de fatores de transcrição, tais como NRF-1, MEF2 e HDACs, e induz biogênese mitocondrial no músculo esquelético 30,31.

Oscilações no conteúdo de cálcio durante a contração muscular, sinalizam a atividade quinase da proteína dependente de calmodulina (CaMKs), que são uma classe de proteínas serina/treonina quinase envolvidas na plasticidade muscular ${ }^{32}$. A isoforma CaMKII predominante no músculo esquelético de seres humanos é altamente expressa em exercícios com intensidade extenuante, possivelmente devido adicional recrutamento de fibras musculares nesta condição; e a alta concentração de cálcio durante a formação das pontes cruzadas na contração muscular ${ }^{28,33}$. Evidências mostram que a CaMKII e a sinalização do cálcio influenciam no transporte/captação de glicose, na captação e oxidação de gorduras, e na adaptação funcional do músculo esquelético ${ }^{34}$. A expressão dos fatores de transcrição no músculo esquelético, tais como CREB (cAMP response element-binding protein), MEF2 e HDACs, são alvos da CaMKIII2.

Fatores de crescimento, citocinas e o estresse celular, tais como a contração muscular, ativam a extensa família de proteínas quinase ativadas por mitógeno (MAPK): (1) Extracellular-Regulated Kinase (ERK1/2), (2) c-Jun N-terminal Kinase (JNK), e (3) p38 MAPK ${ }^{35}$. Evidências mostram que a expressão de $p 38$ MAPK no exercício está relacionado ao status de energia, ${ }^{35}$ enquanto que a predominância das contrações concêntricas ou excêntricas está relacionado a ativação das outras vias ERK1/2 e JNK ${ }^{36}$. Assim, uma larga variedade de processos fisiológicos, tais como a diferenciação, hipertrofia e a inflamação, são regulados pelos eventos transcricionais desencadeados por fosforilação das MAPKs em diversos substratos localizados no citoplasma e no núcleo ${ }^{35,36}$.

Em termos de adaptação mitocondrial e angiogênese do músculo esquelético em resposta ao exercício, foi demonstrado, em linhas gerais, que durante a contração muscular, a expressão de p38MAPK pode estimular a transcrição de PGC-1 a, a activating transcription factor 2 (ATF2), e MEF2 ${ }^{15,28,37}$. Uma das principais considerações a respeito da expressão gênica na mitocôndria refere-se a produção de ROS, no músculo esquelético, durante eventos como a contração muscular. Essa produção de ROS ocorre via geração de superóxidos pelos complexos I e III da cadeia 


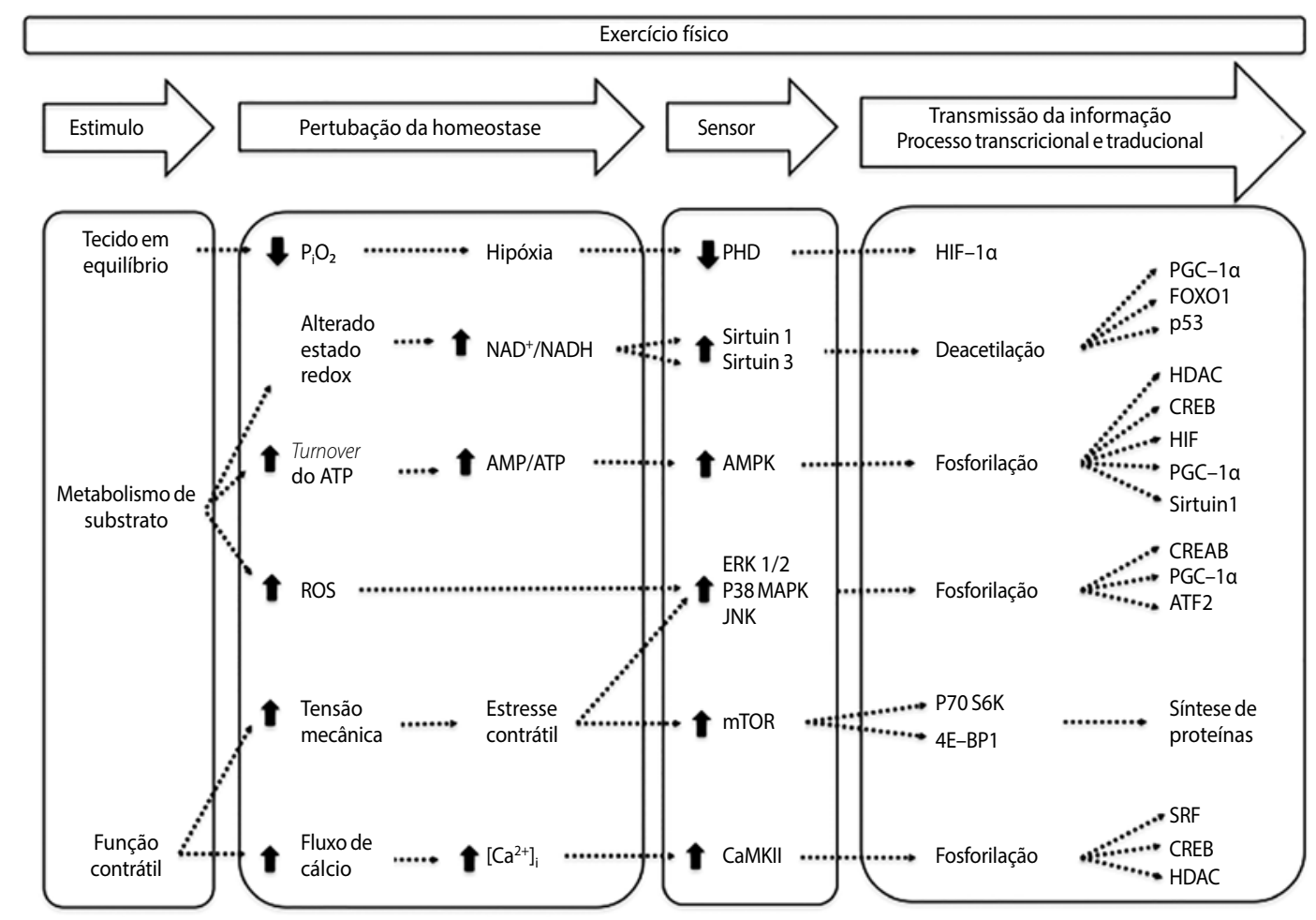

Figura adaptada de Egan e Zierath. ${ }^{2}$

Figura 2. Adaptações moleculares do músculo esquelético ao exercício físico. PGC-1a: Peroxisome proliferator-activated receptor gamma coactivator 1-alpha; FOXO1: Forkhead transcription factor; p53: Tumor protein p53; HDAC: Histone deacetylase; CREB: cyclic AMP response element binding protein; HIF: hypoxia-inducible factor; ATF2: activating transcription factor 2; SRF: Serum response factor.

transportadora de elétrons e pela atividade NADPH oxidase e xantina oxidase. Isto mostra uma grande influência da produção e atividade de ROS na expressão e atividade das MAPKs, no músculo esquelético durante o exercício, ativando a sinalização MAPK pela expressão de ativadores JNK, de interleucina-6 (IL-6) e do fator nuclear Kappa-light-chain-Enhancer of Activated B Cells (NF-kB), ${ }^{38}$ por sua vez atesta a importante sinalização das MAPKs sobre as adaptações metabólicas promovidas pelo exercício.

Trabalhos demonstram que a nicotinamida adenina dinucleotídeo $\left(\mathrm{NAD}^{+}\right)$é um composto orgânico (coenzima) encontrado nas células de todos os seres vivos e usado como "transportador de elétrons" nas reações metabólicas de oxirredução, apresentando um papel preponderante na produção de energia (ATP) para a célula através de sua redução a NADH durante a glicólise no citosol ou com participação do $\mathrm{O}_{2}$ na mitocôndria. Nesse contexto, as proteínas sirtuinas (SIRT) são uma família de deacetilases dependentes de NAD+39. A SIRT1 está presente, predominantemente, no citoplasma e núcleo, enquanto que a SIRT3 está presente na mitocôndria, assim, altamente sensíveis a elevação de $\mathrm{NAD}^{+}$. Assim, a atividade deacetilase dos resíduos de lisina e subsequente aumento da atividade da SIRT sobre os reguladores transcricionais e enzimas mitocondriais, desencadeia alterações no estado redox celular promovendo mudanças adaptativas na expressão gênica e metabolismo celular no músculo esquelético ${ }^{40}$, resultando em aumento da função mitocondrial e desempenho no exercício ${ }^{41}$. Em roedores, foi demonstrado que ocorreu elevação da atividade da SIRT1, três horas após exercício, coincidindo com o aumento da razão $\mathrm{NAD}^{+} / \mathrm{NADH}^{42}$. Outro trabalho demonstrou que após treinamento intervalado houve aumento da expressão da SIRT1 e SIRT3 no músculo esquelético de indivíduos treinados quando comparado aos indivíduos sedentários ${ }^{43}$. Curiosamente, na condição de resistência a insulina no músculo esquelético, foi observada redução da expressão de SIRT344, o que pode, parcialmente, explicar os efeitos terapêuticos do exercício sobre a indução de função mitocondrial e aumento de atividade da SIRT3 em diversas disfunções músculo esqueléticas.

A aplicação de tensão (força) gerada pela contração muscular, desencadeia uma sobrecarga mecânica que define a síntese de proteínas, largamente determinado pela sinalização da Mammalian Target of Rapamycin (mTOR) e pela proteína ribossomal S6K (p70S6K). Dessa forma, a p70S6K é um regulador indispensável para a síntese de proteínas e biogênese ribossomal que envolve a participação do Eukaryotic Translation Initiation Factor 4E (elF4E), Binding Protein (4E-BP1) e o Elongation Factor 2 (eEF2). A fosforilação da 4E-BP1 pela mTOR suprime a ligação e inibição da elF4E, formando um complexo ativo que inicia a tradução. Adicionalmente, a fosforilação da p70S6K leva a fosforilação da 40 S Ribosomal Protein 56 (rpS6) e elF4B, que coletivamente ativam a síntese de proteínas ${ }^{45}$.

Nesse contexto, o exercício aeróbico induz alterações celulares importantes, porém ainda pouco conhecidas, denominadas genericamente de biogênese mitocondrial, com aumento de número, densidade e volume de mitocôndrias, processo denominado de biogênese mitocondrial. Contudo, estudos em células musculares demonstraram que o balanço energético exerce grande influência sobre a quantidade e atividade mitocondrial, estimulando ou inibindo os processos de fissão e fusão de mitocôndrias ${ }^{12}$. Uma vez que o tecido muscular esquelético é rico em mitocôndrias e altamente dependente da fosforilação oxidativa para a produção de energia, não surpreende o fato de que o aumento da capacidade aeróbica induzida pelo exercício ocorra em grande parte devido às adaptações mitocondriais. Durante o exercício extenuante, por exemplo, observa-se aumento de 30 a 40 vezes do fluxo sanguíneo e do consumo de oxigênio intramuscular. De forma similar, a atividade do ciclo do ácido cítrico aumenta em 70 a 100 vezes nas mesmas condições ${ }^{12}$.

Holloszy ${ }^{46}$ foi o primeiro a demonstrar que apenas seis semanas de exercício físico, predominantemente aeróbico, foi capaz de dobrar o conteúdo mitocondrial e a capacidade oxidativa muscular. Hood ${ }^{47}$ 
demostrou que após seis semanas de exercício aeróbico, a densidade mitocondrial no músculo esquelético aumentou cerca de 100\%. Estas descobertas ocorreram a quase cinco décadas e no início da década passada ocorreram avanços significativos no sentido de elucidar os mecanismos moleculares que coordenam essas respostas. Assim, diversos estudos demonstraram que uma única sessão de exercício aeróbico é capaz de aumentar rapidamente a expressão de Peroxisome Proliferator-Activated Receptor Gamma Coactivator-1alpha (PGC-1a), um cofator de transcrição chave na atividade de diversos fatores de transcrição nuclear, como os fatores respiratórios nucleares 1 e 2 (NRF-1 e NRF-2) e de transcrição mitocondrial A (Tfam), responsável pela transcrição e a replicação do mtDNA ${ }^{48}$.

Os fatores NRF1 e 2 são requeridos para a biogênese mitocondrial e os receptores nucleares alfa relacionados ao estrogênio (EERa) induzem a expressão de genes que regulam a fosforilação oxidativa, biogênese mitocondrial e a síntese de ATP. Ambos, fatores NRF1, NRF2 e receptores EERa, mostraram-se elevados no tecido muscular em resposta a oxidação de ácidos graxos ${ }^{49}$. Nesse contexto, o fator de transcrição Myocyte Enhancer Factor 2 (MEF2) induziu aumento de fibras musculares oxidativas e no conteúdo de PGC-1a no músculo esquelético em resposta ao exercício aeróbico ${ }^{50}$.

Nesse contexto, o músculo esquelético é caracterizado por possuir uma elevada expressão de Peroxisome Proliferator-Activated Receptor Beta (PPARß). Esta proteína é abundante em fibras musculares oxidativas (tipo I). Assim, a ativação do receptor PPARß no músculo esquelético tem sido considerado um mecanismo essencial durante o exercício prolongado, promovendo aumento da oxidação de ácidos graxo. Tem sido demonstrado que a ativação do receptor PPARß no músculo esquelético induz a expressão de genes envolvidos no metabolismo, tais como Fatty Acid Transport Protein Family (FATP), Hormone Sensitive Lipase (HSL), Long-Chain Acyl-COA Dehydrogenase (LCAD), PGC-1a, Mitochondrial Uncoupling Protein (UCP2 e 3), Pyruvate Dehydrogenase Kinase 4 (PDK4) e Carnitine Palmitoyl Transferase 1 (CPT1) 51 . A função do PPARß no metabolismo muscular foi também demonstrado em estudo com camundongos PPAR $\beta \mathrm{KO}$, em que a expressão de genes-alvo Lipoprotein Lipase (LPL), Long-Chain Acyl COA Synthase (LCAS), Medium-Chain Acyl COA Dehydrogenase (MCAD), HADHA, UCP3 e PGC-1 a foram significativamente reduzidas, além da diminuição do número de fibras musculares oxidativas ${ }^{52}$.

A presença de níveis elevados de diacilglicerol no músculo esquelético de indivíduos treinados mostrou indução da proteína quinase C (PKC), que desativa a sinalização da insulina ${ }^{53}$. Nesse contexto, mudanças na expressão e atividades de proteínas que regulam o metabolismo de gorduras no músculo esquelético em resposta ao exercício aeróbico tem sido relatadas, tais como os reguladores Stearoyl-CoA desaturase-1 (SCD1), Diacylglycerol Acyltransferase-1 (DGAT1), Lipolysis-Related Proteins (ATGL) e Comparative Gene Identification 58 (CGI-58) ${ }^{53}$.

As proteínas Perilipin 2 e 5 (PLIN2 e PLIN5) são importantes reguladores do metabolismo de gorduras no músculo esquelético ${ }^{54}$. A proteína PLIN2 é essencial para o estoque de triglicérides intramusculares e inibição da lipólise ${ }^{54}$. Sendo, portanto, a expressão das proteínas PLIN2 e PLIN5 altamente reguladas no exercício aeróbico. Foi demonstrado que indivíduos idosos exercitados tiveram maior expressão de PLIN5 em comparação com sedentários ${ }^{51}$ e que jovens atletas possuíam elevada expressão de PLIN2 e PLIN5 quando comparados aos controles ${ }^{54}$.

Mais recentemente, o músculo esquelético tem ganhado o status de órgão endócrino, acumulando evidências de que durante o exercício, este tecido tem produzido e secretado citocinas e peptídeos ativos (miocinas) na circulação ${ }^{55}$. Estas miocinas tem exercido papel endócrino sobre o tecido adiposo, fígado, intestino e pâncreas, ou efeito parácrino/ autócrino localmente. A IL-6 é uma das muitas miocinas que exercem uma variedade de efeitos envolvidos com a adaptação do músculo esquelético ao exercício, incluindo a hipertrofia e angiogênese ${ }^{55}$. Outra miocina descoberta mais recentemente é a Irisina que possui um papel sobre o "escurecimento" do tecido adiposo branco, elevando o gasto de energia basal e atenuando a resistência a insulina induzido pela dieta em roedores ${ }^{56}$. Estes achados, claramente demonstram o papel do músculo esquelético como órgão secretório que representa uma intrigante via para pesquisas translacionais, embora a extensão desta regulação em resposta ao exercício seja ainda desconhecida.

Um emergente paradigma da regulação molecular pós-transcricional exercido pelo exercício físico no músculo esquelético envolve a ação de microRNAs (miRNA), que inibem a tradução de proteínas ou aumentam a degradação do RNA. Por exemplo, o miRNA-499 codificado pelo gene Myosin Heavy Chain (MHC-I), sendo que a forma Myh7b, é proposta como regulador do tipo de fibra pela diminuição da expressão de Sox6, Purb e Sp3, uma vez que são repressoras da expressão de MHC-I. Adicionalmente, promovendo a conversão de fibras tipo Il para tipo I, coincidindo com a elevação do metabolismo oxidativo em roedores e a melhora do desempenho de corrida em esteira ${ }^{57}$. Contudo, as implicações sobre as mudanças adaptativas da expressão de genes no músculo esquelético ainda não são claras, requerendo estudos adicionais para fundamentar as hipóteses ${ }^{57}$.

Em termos gerais, estas adaptações moleculares do músculo esquelético ao exercício físico refletem o aumento do conteúdo de proteínas envolvidas na síntese de ATP mitocondrial, elevação de proteínas envolvidas no ciclo de Krebs, maior mobilização, transporte e oxidação de ácidos graxos, eficaz metabolismo glicolítico, maior capacidade antioxidante, eficiente transporte/captação de glicose e síntese de glicogênio, e aumento da entrega e extração de $\mathrm{O}_{2}$ para o músculo esquelético, ${ }^{12,46,58}$ sendo influenciadas por fatores intrínsecos, principalmente pela intensidade e duração do exercício; por fatores metabólicos, que incluem o padrão de recrutamento de fibras musculares, atividade enzimática e conteúdo de substratos; e por fatores extrínsecos, que incluem as condições do ambiente, status nutricional, idade e a composição corporal ${ }^{59,60}$. Corroborando para o maior desempenho de atletas em competições esportivas e ainda, mais recentemente, como terapia (não farmacológica) contra disfunções músculo esqueléticas relacionadas a perda de massa muscular, como por exemplo a sarcopenia no envelhecimento ou a caquexia no câncer.

\section{CONSIDERAÇÕES FINAIS}

As bases moleculares das alterações moleculares pelo músculo esquelético em resposta ao exercício tem sido, recentemente, uma área de interesse entre os pesquisadores. A Biologia Molecular, o estudo das ômicas, juntamente com a Bioinformática e da Biologia de Sistemas, atualmente, vêm focando uma intricada rede de vias de sinalização e moléculas reguladoras que coordenam a resposta adaptativa do músculo esquelético ao exercício e proposto tais modificações como um importante instrumento terapêutico contra desordens metabólicas.

Os efeitos pleiotrópicos do exercício e a complexidade das respostas moleculares sugerem que as múltiplas vias de sinalização convergem para promover uma conformação do músculo esquelético ao exercício, embora a viabilidade dessas vias permaneça ainda por serem determinadas ou melhores estudadas. Neste trabalho, foram apresentados dezenas de marcadores moleculares obtidos em estudos recentes, sobressaindo-se evidências de que os benefícios do exercício contra as disfunções metabólicas e prevenção de doenças crônicas podem ser mediadas, pelo menos em parte, pela complexa rede molecular de vias de sinalização que regulam a transcrição e tradução de proteínas no músculo esquelético. 


\section{AGRADECIMENTOS}

Este estudo teve suporte financeiro da Fundação de Amparo à Pesquisa do Estado de São Paulo (FAPESP), do Estado do Ceará (Fundação Cearense de Apoio ao Desenvolvimento Científico e Tecnológico FUNCAP), Coordenação de Aperfeiçoamento de Pessoal de Nível
Superior (CAPES) e Conselho Nacional de Desenvolvimento Científico e Tecnológico (CNPq).

Todos os autores declararam não haver qualquer potencial conflito de interesses referente a este artigo.

CONTRIBUIÇÕES DOS AUTORES: Cada autor contribuiu individual e significativamente para o desenvolvimento do manuscrito. PA (0000-0002-4143-6949)* e VMC (0000-0003-4839-4400)* foram os principais contribuintes na redação do manuscrito. PA e VMC realizaram a pesquisa bibliográfica. JHLC (0000-0002-3972-1361)*, PA e VMC, revisaram o manuscrito e contribuíram igualmente para o conceito intelectual do estudo. PA, VMC e JHLC revisaram e aprovaram a versão final do manuscrito. *ORCID (Open Researcher and Contributor ID).

\section{REFERÊNCIAS}

1. Kelly SA, Villena FP, Pomp D. The'omics' of voluntary exercise: systems approaches to a complex phenotype. Trends Endocrinol Metab. 2015;26(12):673-5.

2. Borst SE. Interventions for sarcopenia and muscle weakness in older people. Age Ageing. 2004;33(6),548-55.

3. Coffey VG, Hawley JA. The molecular bases of training adaptation. Sports Med. 2007;37(9):737-63.

4. Widrick JJ, Stelzer JE, Shoepe TC, Garner DP. Functional properties of human muscle fibers after short-term resistance exercise training. Am J Physiol Regul Integr Comp Physiol. 2002;283(2):408-16.

5. Spina RJ, Chi MM, Hopkins MG, Nemeth PM, Lowry OH, Holloszy JO. Mitochondrial enzymes increase in muscle in response to 7-10 days of cycle exercise. J Appl Physiol. 1996;80(6):2250-4.

6. Green HJ, Helyar R, Ball-Burnett M, Kowalchuk N, Symon S, Farrance B. Metabolic adaptations to training precede changes in muscle mitochondrial capacity. J Appl Physiol. 1992;72(2):484-91.

7. Benziane B, Burton TJ, Scanlan B, Galuska D, Canny BJ, Chibalin AV, et al. Divergent cell signaling after short-term intensified endurance training in human skeletal muscle. Am J Physiol Endocrinol Metab. 2008;295(6):E1427-38.

8. Pilegaard $\mathrm{H}$, Saltin $\mathrm{B}$, Neufer PD. Exercise induces transient transcriptional activation of the PGC-1alpha gene in human skeletal muscle. J Physiol. 2003;546(Pt 3):851-8.

9. Sin DD, McAlister FA, Man SF, Anthonisen NR. Contemporary management of chronic obstructive pulmonary disease: scientific review. JAMA. 2003;290(17):2301-12

10. Coffey VG, Shield A, Canny BJ, Carey KA, Cameron-Smith D, Hawley JA. Interaction of contractile activity and training history on mRNA abundance in skeletal muscle from trained athletes. Am J Physiol Endocrinol Metab. 2006;290(5):E849-55

11. Holloszy JO, Coyle EF. Adaptations of skeletal muscle to endurance exercise and their metabolic consequences. J Appl Physiol Respir Environ Exerc Physiol. 1984;56(4):831-8.

12. Egan B, Zierath JR. Exercise metabolism and the molecular regulation of skeletal muscle adaptation. Cell Metab. 2013;17(2):162-84

13. Yu M, Blomstrand E, Chibalin AV, Krook A, Zierath JR. Marathon running increases ERK1/2 and p38 MAP kinase signalling to downstream targets in human skeletal muscle. J Physiol. 2001;536(Pt 1):273-82.

14. McGee SL, Fairlie E, Garnham AP, Hargreaves M. Exercise-induced histone modifications in human skeletal muscle. J Physiol. 2009;587(Pt 24):5951-8.

15. Wright DC, Han DH, Garcia-Roves PM, Geiger PC, Jones TE, Holloszy JO. Exercise-induced mitochondrial biogenesis begins before the increase in muscle PGC-1alpha expression. J Biol Chem. 2007;282(1):194-9,

16. Little JP, Safdar A, Bishop D, Tarnopolsky MA, Gibala, MJ. An acute bout of high-intensity interval training increases the nuclear abundance of PGC-1a and activates mitochondrial biogenesis in human skeletal muscle. Am J Physiol Regul Integr Comp Physiol. 2011;300(6):R1303-10.

17. Safdar A, Bourgeois JM, Ogborn DI, Little JP, Hettinga BP, Akhtar M, et al. Endurance exercise rescues progeroid aging and induces systemic mitochondrial rejuvenation in mtDNA mutator mice. Proc Nat Acad Sci USA. 2011;108(10):4135-40.

18. Barrès R, Yan J, Egan B, Treebak JT, Rasmussen M, FritzT,et al. Acute exercise remodels promoter methylation in human skeletal muscle. Cell Metab. 2012;15(3):405-11.

19. Booth FW, Thomason DB. Molecular and cellular adaptation of muscle in response to exercise: perspectives of various models. Physiol Rev. 1991;71(2):541-85.

20. Taylor CT. Mitochondria and cellular oxygen sensing in the HIF pathway. Biochem J. 2008;409(1):19-26.

21. Schmutz S, Däpp C, Wittwer M, Vogt M, Hoppeler H, Flück M. Endurance training modulates the muscular transcriptome response to acute exercise. Pflugers Arch. 2006;451(5):678-87.

22. Jiang BH, Rue E, Wang GL, Roe R, Semenza GL. Dimerization, DNA binding, and transactivation properties of hypoxia-inducible factor 1. J Biol Chem. 1996:271(30):17771-8.

23. Richardson RS, Noyszewski EA, Kendrick KF, Leigh JS, Wagner PD. Myoglobin O2 desaturation during exercise. Evidence of limited O2 transport. J Clin Invest. 1995;96(4):1916-26.

24. Ameln H, Gustafsson T, Sundberg CJ, Okamoto K, Jansson E, Poellinger L, Makino Y. Physiological activation of hypoxia inducible factor-1 in human skeletal muscle. FASEB J. 2005;19(8):1009-11.

25. Formenti F, Constantin-Teodosiu D, Emmanuel Y, Cheeseman J, Dorrington KL, Edwards LM, et al. Regulation of human metabolism by hypoxia-inducible factor. Proc Natl Acad Sci USA. 2010;107(28):12722-7.

26. Jäger S, Handschin C, St-Pierre J, Spiegelman BM AMP-activated protein kinase (AMPK) action in skeletal muscle via direct phosphorylation of PGC-1 alpha. Proc Natl Acad Sci USA. 2007;104(29):12017-22

27. Kahn BB, Alquier T, Carling D, Hardie DG. AMP-activated protein kinase: ancient energy gauge provides clues to modern understanding of metabolism. Cell Metab. 2005;(1):15-25.

28. Egan B, Carson BP, Garcia-Roves PM, Chibalin AV, Sarsfield FM, Barron N, et al. Exercise intensity-dependent regulation of peroxisome proliferator-activated receptor coactivator-1 mRNA abundance is associated with differential activation of upstream signalling kinases in human skeletal muscle. J Physiol. 2010;588(Pt 10):1779-90.

29. Wojtaszewski JF, Nielsen P, Hansen BF, Richter EA, Kiens B. Isoform-specific and exercise intensity-dependent activation of 5'-AMP-activated protein kinase in human skeletal muscle. J Physiol. 2000;528(Pt 1):221-6.

30. McGee SL, van Denderen BJ, Howlett KF, Mollica J, Schertzer JD, Kemp BE, et al. AMP-activated protein kinase regulates GLUT4 transcription by phosphorylating histone deacetylase 5. Diabetes. 2008:57(4):860-7.

31. Bergeron R, Ren JM, Cadman KS, Moore IK, Perret P, Pypaert M, et al. Chronic activation of AMP kinase results in NRF-1 activation and mitochondrial biogenesis. Am J Physiol Endocrinol Metab. 2001;281(6):E1340-6.
32. Chin ER. Intracellular Ca2+ signaling in skeletal muscle: decoding a complex message. Exerc Sport Sci Rev. 2010;38(2):76-85.

33. Rose AJ, Kiens B, Richter EA. Ca2+-calmodulin-dependent protein kinase expression and signalling in skeletal muscle during exercise. J Physiol. 2006;574(Pt 3):889-903.

34. Raney MA, Turcotte LP. Evidence for the involvement of CaMKII and AMPK in Ca2+-dependent signaling pathways regulating FA uptake and oxidation in contracting rodent muscle. J Appl Physiol. 2008;104(5):1366-73.

35. Coffey VG, Zhong Z, Shield A, Canny BJ, Chibalin AV, Zierath JR, et al. Early signaling responses to divergent exercise stimuli in skeletal muscle from well-trained humans. FASEB J. 2006;20(1):190-2.

36. Wretman C, Lionikas A, Widegren U, Lännergren J, Westerblad H, Henriksson J. Effects of concentric and eccentric contractions on phosphorylation of MAPK (erk1/2) and MAPK(p38) in isolated rat skeletal muscle. J Physiol. 2001;535(Pt 1):155-64.

37. Pogozelski AR, Geng T, Li P, Yin X, Lira VA, Zhang M, Chi JT, Yan Z. p38gamma mitogen-activated protein kinase is a key regulator in skeletal muscle metabolic adaptation in mice. PLoS One. 2009:4(11):e7934.

38. Whitham M, Chan MH, Pal M, Matthews VB, Prelovsek O, Lunke S, et al. Contraction-induced interleukin-6 gene transcription in skeletal muscle is regulated by c-Jun terminal kinase/activator protein-1. J Biol Chem. 2012;287(14):10771-9.

39. Schwer B, Verdin E. Conserved metabolic regulatory functions of sirtuins. Cell Metab. 2008;7(2):104-12

40. Lagouge M, Argmann C, Gerhart-Hines Z, Meziane H, Lerin C, Daussin F, et al. Resveratrol improves mitochondrial function and protects against metabolic disease by activating SIRT1 and PGC-1alpha. Cell. 2006; 127(6):1109-22.

41. Gerhart-Hines Z, Rodgers JT, Bare O, Lerin C, Kim SH, Mostoslavsky R, et al. Metabolic control of muscle mitochondrial function and fatty acid oxidation through SIRT1/PGC-1alpha. EMBO J. 2007;26(7):1913-23.

42. Cantó C, Gerhart-Hines Z, Feige JN, Lagouge M, Noriega L, Milne JC, et al. AMPK regulates energy expenditure by modulating NAD+ metabolism and SIRT1 activity. Nature. 2009;458(7241):1056-60.

43. Little JP, Safdar A, Wilkin GP, Tarnopolsky MA, Gibala MJ. A practical model of low-volume high-intensity interval training induces mitochondrial biogenesis in human skeletal muscle: potential mechanisms. J Physiol. 2010;588(Pt 6):1011-22

44. Jing E, Emanuelli B, Hirschey MD, Boucher J, Lee KY, Lombard D, et al. Sirtuin-3 (Sirt3) regulates skeletal muscle metabolism and insulin signaling via altered mitochondrial oxidation and reactive oxygen species production. Proc Natl Acad Sci USA. 2011;108(35):14608-13.

45. Sandri, M. Signaling in muscle atrophy and hypertrophy. Physiology (Bethesda). 2008;23,160-70.

46. Holloszy JO. Biochemical adaptations in muscle. Effects of exercise on mitochondrial oxygen uptake and respiratory enzyme activity in skeletal muscle. J Biol Chem. 1967;242(9):2278-82.

47. Hood DA. Invited review: contractile activity-induced mitochondrial biogenesis in skeletal muscle. J App I Physiol. 2001;90(3):1137-57.

48. Puigserver P, Wu Z, Park CW, Graves R, Wright M, Spiegelman BM. A cold-inducible coactivator of nuclear receptors linked to adaptive thermogenesis. Cell. 1998;92(6):829-39.

49. Wu Z, Puigserver P, Andersson U, Zhang C, Adelmant G, MoothaV, et al. Mechanisms controlling mitochondrial biogenesis and respiration throught he thermogenic coactivator PGC-1. Cell. 1999;98(1):115-24.

50. Czubryt MP, McAnally J, Fishman Gl, Olson EN. Regulation of peroxisome proliferator-activated receptor gamma coactivator 1 alpha (PGC-1 alpha) and mitochondrial function by MEF2 and HDAC5. Proc Nat Acad Sci USA. 2003;100(4):1711-6.

51. NarkarVA, Downes M, Yu RT, Embler E, Wang YX, Banayo E, et al. AMPK and PPARdelta agonists are exercise mimetics. Cell. 2008;134(3):405-15.

52. Schuler M, Ali F, Chambon C, Duteil D, Bornert JM, Tardivel A, et al. PGC1alpha expression is controlled in skeletal muscles by PPARbeta, whose ablation results in fiber-type switching, obesity, and type 2 diabetes. Cell Metab. 2006;4(5):407-14

53. Amati F, Dubé JJ, Alvarez-Carnero E, Edreira MM, Chomentowski P, Coen PM, et al. Skeletal muscle triglycerides, diacylglycerols, and ceramides in insulin resistance: another paradox in endurance-trained athletes? Diabetes. 2011;60(10):2588-97.

54. Bosma M, Hesselink MK, Sparks LM, Timmers S, Ferraz MJ, Mattijssen F, et al. Perilipin 2 improves insulin sensitivity in skeletal muscle despite elevated intramuscular lipid levels. Diabetes. 2012;61(11):2679-90.

55. Pedersen BK, Febbraio MA. Muscles, exercise and obesity: skeletal muscle as a secretory organ. Nat Rev Endocrinol. 2012;8(8):457-65.

56. Boström P, Wu J, Jedrychowski MP, Korde A, Ye L, Lo JC, et al. A PGC1-a-dependent myokine that drives brown-fat-like development of white fat and thermogenesis. Nature. 2012;481(7382):463-8.

57. van Rooij E, Quiat D, Johnson BA, Sutherland LB, Qi X, Richardson JA, et al. A family of microRNAs encoded by myosin genes governs myosin expression and muscle performance. Dev Cell. 2009;17(5):662-73.

58. Gavin TP, Ruster RS, Carrithers JA, Zwetsloot KA, Kraus RM, Evans CA, et al. No difference in the skeleta muscle angiogenic response to aerobic exercise training between young and aged men. J Physiol. 2007:585(Pt 1):231-9.

59. Brooks GA. Mammalian fuel utilization during sustained exercise. Comp Biochem Physiol B Biochem Mol Biol. 1998;120(1):89-107.

60. Spriet LL, Watt MJ. Regulatory mechanisms in the interaction between carbohydrate and lipid oxidation during exercise. Acta Physiol Scand. 2003;178(4):443-52. 